\title{
Prensa deportiva nacional y regional en España
}

\author{
Clara SAInZ DE BARANDA ANDÚJAR \\ Universidad Carlos III de Madrid \\ cbaranda@hum.uc3m.es
}

\section{Resumen:}

La información deportiva en España es un ámbito de enorme complejidad como fenómeno social contemporáneo. El presente trabajo tiene como finalidad principal analizar la prensa deportiva española, acometiendo una reflexión sobre su trayectoria en los últimos años, su evolución, lectores y contenidos. El panorama actual de la prensa deportiva en España está gobernado por cuatro cabeceras: Marca, $A s$, Sport y Mundo Deportivo. Pero también existen otras cabeceras especializadas en el tema de difusión local o regional que permanecen en el mercado, las más destacadas son: DxT.Deporte Campeón, Super Deporte, ESTADIO Deportivo y El 9 Espotiu de Catalunya, todos ellos impresos.

Palabras clave: prensa; información deportiva; España; lectores; nacional; regional.

\section{Sports information in Spain: national and regional}

\begin{abstract}
:
Sports information in Spain is an area of enormous complexity as contemporary social phenomenon. This work has as main purpose to analyze the Spanish sports press, undertaking a reflection on his career in recent years, its evolution, readers and content.

The current landscape of the sports press in Spain is governed by four heads: Marca, As, Sport and Mundo Deportivo. But there are other specialized headers on the issue of local or regional spread that remain on the market, the most prominent are: DxT.Deporte Campeón, Super Deporte, ESTADIO Deportivo and El 9 Espotiu de Catalunya, all printed.
\end{abstract}

Key Words: news; sports news; Spain; readers; national; regional.

\section{Referencia normalizada:}

Sainz de Baranda Andújar, C. (2014): Prensa deportiva nacional y regional en España. Historia y Comunicación Social. Vol. 19. Núm. Especial Febrero. Págs. 107-118.

Sumario: 1. Introducción. 2. Metodología. 3. Diarios deportivos en España. 3.1. Mundo Deportivo. 3.2. Marca. 3.3. As. 3.4. Sport. 3.5. Super Deporte. 3.6. DxT.Deporte Campeón. 3.7. ESTADIO Deportivo. 3.8. El 9 Espotiu de Catalunya. 4. Conclusiones. 5. Bibliografía

\section{Introducción}

La información deportiva, caracterizada por la sencillez del relato, está dirigida a toda clase de público masivo -los lectores no responden a un perfil concreto, millones de personas, sin distinción de credo, edad, formación o condición social-, lo que se refleja en un crecimiento espectacular en el número de lectores en los últimos tiempos. 
Sin embargo, curiosamente, el deporte como fenómeno cultural en los medios de comunicación parece atraer menos atención de los investigadores (Boyle, Rowe y Whannel, 2009). Es difícil encontrar una definición de prensa deportiva actualizada y acorde con la realidad del siglo XXI, al igual que ocurre con la definición de prensa, de ahí la revisión del concepto de prensa, periodismo especializado y, para concluir, de la prensa deportiva.

Diferentes autores se centran en las definiciones de prensa especializada y periodismo especializado (Martínez Albertos, 1983; Paniagua, 2003; Fernández del Moral, 2004; Esteve y Fernández del Moral, 2007). Sin embargo, los periódicos deportivos se consideran prensa especializada pero dirigida a un público generalista. Para Antonio Alcoba (2005:157):

La prensa específicamente deportiva debe competir con los diarios de información general, la radio y la televisión, conociendo sus limitaciones para enfrentarse, como negocio, a los restantes medios de comunicación. La prensa de información general ofrece tratamientos de todos los temas, incluido el deporte, y por esta característica posee una gran ventaja: el interés de los clientes, traducido en más venta y mayor atractivo para la publicidad.

El deporte configura secciones autónomas en la prensa y es objeto de especialización en cuanto a su coherencia temática y tratamiento específico de la información con un lenguaje propio, uso de fuentes concretas, rutinas productivas, audiencia a la que va dirigida y existencia de periodistas especializados (Palacios, 1999: 356). Al igual que ocurre en los medios de comunicación generalistas el contenido es muy parecido pero, en lugar de tendencias ideológicas, la principal diferencia es el mayor seguimiento a unos determinados equipos o actividades deportivas (Marrone, 2009: 27). De esta forma, los periódicos catalanes cubren más información de equipos de fútbol como el F.C. Barcelona o el R.C.D. Español, mientras que los madrileños dan más páginas al Real Madrid y al Atlético de Madrid.

Se puede concluir que la prensa deportiva, hoy en día, es un medio especializado -impreso o digital-, cualquiera que sea su periodicidad, que se dirige a un público generalista identificada con el mayor seguimiento a unos determinados equipos o actividades deportivas.

\section{Metodología}

La metodología aplicada parte de la revisión de textos específicos que tratan la historia de la prensa deportiva, así como a la propia investigación empírica. Esta última ha consistido en el análisis de algunos de los periódicos más representativos de este periodo que nos ha facilitado el conocimiento de las cabeceras deportivas más importantes, así como profundizar en algunos detalles relativos a las mismas, como el año de aparición, los cambios en el título de la cabecera, la periodicidad, los directores y redactores, el precio, etc. 


\section{Diarios deportivos en España}

El panorama actual de la prensa deportiva en España está gobernado por cuatro cabeceras: Marca, As, Sport y Mundo Deportivo. Pero también existen otras cabeceras especializadas en el tema, aunque no estrictamente diarios, de difusión local o regional que permanecen en el mercado, las más destacadas son: DxT.Deporte Campeón, Super Deporte, ESTADIO Deportivo y El 9 Espotiu de Catalunya, todos ellos impresos.

\subsection{Mundo Deportivo}

Mundo Deportivo es el decano de los diarios deportivos españoles, en la actualidad, es el único diario español, nacido a principios del siglo XX que sobrevive. En el ámbito mundial es la segunda cabecera con mayor antigüedad que sigue en el mercado por detrás del diario italiano La Gazzetta dello Sport.

Desde que apareció como semanario en Barcelona, el jueves 1 de febrero de 1906, siempre se centró en diferentes deportes, según las tendencias del momento. El Mundo Deportivo, además de la función informativa siempre fue impulsor y organizador de distintas campañas deportivas, fundamentalmente en el ámbito catalán - esta es una característica propia de la prensa de finales del siglo XIX y principios del siglo $\mathrm{XX}$, la de crear, organizar o fomentar competiciones deportivas nuevas - (Sainz de Baranda, 2013).

La periodicidad semanal pasó a ser bisemanal bajo la dirección de Ricardo Grau Escoda, en 1922. Un año después pasó a ser trimestral, poco después cuadrisemanal, hasta que el 4 de marzo de 1929, bajo la dirección de José Torrents Font, se convierte en diario. Durante la Guerra Civil Española, debido a la falta de papel, se convirtió nuevamente en semanario, incluso dejo de publicarse para reaparecer el 31 de diciembre de 1939 (Mundo Deportivo, 1 de febrero de 1956).

Pero, El Mundo Deportivo no fue el primer diario deportivo español; lo fue Excelsior: deportes, información y cultura, $(1924$ - 1932) y su sucesor Excelsius (19321937), editado en Bilbao, en la órbita del Partido Nacionalismo Vasco. Después vinieron El Mundo Deportivo (1929) y, el fallido, Madrid Gran Sport (1930).

A finales del siglo XX, el 6 de julio de 1999, suprime el artículo "El" y pasa a llamarse Mundo Deportivo, con un nuevo logotipo de mayor impacto, aumenta sus páginas a color y la presencia de las columnas de opinión, la imagen se convierte en protagonista.

El decano de la prensa diaria deportiva española es un claro ejemplo de cómo la personalidad de los directores de los periódicos ${ }^{1}$ - solo ocho en más de un siglo -

1 Narcís Masferrer i Sala (1906 - 1920); Ricardo Grau Escoda (1920 - 1929); José Torrens Font (1929 - 1939); José Luís Lasplazas (1939- 1967); Ricardo Grau Escoda (1967 - 1976); Juan José Castillo (1976 - 1988); Manuel Tarín Alonso (1988 - 1991); Santi Nolla (1991- actualidad). 
impregnan al conjunto de la redacción, y aseguran la continuidad de la personalidad del propio diario.

En la actualidad Mundo Deportivo es la cuarta cabecera en lo que respecta al número de lectores, según datos del Estudio General de Medios (EGM)², muy por detrás de las cifras de Marca y As, y por detrás de Sport, su principal competidor.

El EGM recoge datos de Mundo Deportivo desde 1972, con 189.000 lectores al día, pero no se recogen de manera continua hasta 1984. Los datos que el EGM ofrece en los años 1978 y 1979, con 37.000 y 78.000 lectores respectivamente, explican la salida al mercado de Sport en noviembre de 1979. La primera vez que Mundo Deportivo es superado por Sport en número de lectores, es el año 1989 ocupando el cuarto puesto de la prensa deportiva. El tercer puesto lo recupera al siguiente año, pero lo pierde entre 1991 y 1998, en el 2004, entre 2006 y 2007, y entre 2009 y 2012.

La primera vez que Mundo Deportivo supera el medio millón de lectores es en el año 2003, con 506.000, manteniéndose por encima de esta cifra los años consecutivos. Consigue su dato más alto en el año 2011 con 719.000 lectores al día, aunque durante el último año ha perdido 8.000 lectores. En concreto la pérdida registrada entre los años 2011 y 2012 es de un $1,2 \%$.

\subsection{Marca}

En Madrid no llegaba a cuajar la existencia de un diario deportivo como ocurrió en Barcelona o Bilbao. Hubo un intento fallido, como Gran Sport, en 1930: "fundado por Ignacio Valenzuela, dirigido por Ángel Díez de las Heras y con la colaboración de Acisclo Karag; tuvo una vida efimera, durante poco más de dos meses" (Altabella, 1987: 180).

Habrá que esperar a 1940 cuando surge el diario Gol fundado el 4 de agosto por Valeriano Hernández Usobiaga, que con grandes dificultades se publicó hasta 1945 (Altabella, 1987: 182).

Al mismo tiempo, en San Sebastián, se publica el primer número de Marca. Semanario gráfico de los deportes ${ }^{3}$, el miércoles 21 de diciembre de 1938, durante la Guerra Civil española. Su fundador y director fue Manuel Fernández Cuesta y Melero.

En 1940 la redacción de Marca se traslada a Madrid, un cambio lógico en la ambiciosa vocación del semanario. Marca, como toda publicación, se encuentra bajo el control de la Dirección General de la Prensa. A pesar de la situación de España en la posguerra la publicación alcanzó los 140.000 ejemplares en 1942. Así, el 25 de

2 El EGM, elaborado por la Asociación para la Investigación de Medios de Comunicación (AIMC) desde 1968, es un estudio multimedia que analiza el comportamiento de la población respecto a los distintos medios. En concreto, utilizamos los datos que aporta sobre el número de lectores al día, teniendo en cuenta que se refieren a la población española de 14 o más años de edad.

3 Estaba impreso en huecograbado con tinta verde, en tamaño sábana y contaba con 8 páginas. Aportaba gran calidad gráfica para la época y un diseño innovador en la combinación y distribución de fotografías, caricaturas y textos. 
noviembre de 1942, formado por 8 páginas - la última siempre gráfica - y al precio de 30 céntimos, editado en tipografía y en huecograbado, Marca se transforma en diario. (Toro, 2004).

Marca, como no podía ser de otra manera, también se centra en la promoción deportiva, instituye, entre otros galardones anuales el Premio Pichichi y el Trofeo Zamora, seis años después.

En 1964 el diario es adquirido por la empresa Espacio Editorial. En febrero de 1973, Carmelo Martínez González es nombrado director - lo será 10 años -, con él al cargo llegan otros tiempos, surge la competencia directa en Madrid, el diario As. Las cifras de tirada corroboran la competencia y se produce un descenso: "en 1965 se tiraban 147.111 ejemplares; en 1976, 96.041; en 1979, 92.041; en 1978. 90.694..." (Altabella 1988: 185).

Aunque Marca siempre identifica con los equipos madrileños, en concreto con el Real Madrid, nunca se ha despreocupado de los equipos de fútbol de otras provincias y, en menor medida, de los deportes minoritarios, lo que le ha permitido desde 1988 - cuando superó a $A s$ - ser el diario de tirada nacional deportivo más leído, y desde el año 2000 supera a todos los de información general. En los últimos datos del EGM 2012, como profundizamos más adelante, Marca con 3.0011 .000 lectores al día, supera así en 100.000 lectores a la suma de los otros tres diarios que acumulan 2.911.000 lectores.

En la actualidad, Óscar Campillo es su director ${ }^{1}$, se ha desarrollado a través de todos los soportes con una Web también líder, Radio Marca y, desde agosto de 2010, Marca TV.

\subsection{As}

El número uno de $A s$ apareció en los quioscos el 6 de diciembre de 1967 con una tirada de 60.000 ejemplares. Se creó tomando el nombre de una anterior publicación, el Semanario Gráfico As que se editó desde 1932 hasta 1936.

Desde el principio Apostó por el fútbol, por los equipos madrileños, pero no descuidó otros deportes como baloncesto, motor, boxeo, atletismo o tenis. Fundado por Luis Montiel Balanzat $(1884-1976)^{2}$, nace con carácter diario para competir con Marca a nivel nacional.

1 Desde su aparición en 1938, Marca ha contado con 16 directores: Manuel Fernández Cuesta (1938-1945); Ibrahim Malcervelli (1945-1946); Manuel Casanova (1946-1947), Lucio del Álamo (1947-1954); Nemesio Fernández Cuesta (1954-1973); Carmelo Martínez (1973-1983); Valentín Martín (1983-1984); Juan Pablo Villanueva (1984- 1986); Jesús Ramos (1986-1987); Luis Infante (1987-1997); Manuel Saucedo (1997-2001); Elías Israel (2011-2005); Manuel Saucedo (2005-2006); Alejandro Sopeña (2006-2007); Eduardo Inda (2007- 2011); Oscar Campillo (2011- actualidad).

2 Luis Montiel Balanzat pertenece a la familia de editores Montiel, propietario de la sociedad editora Semana S.L. desde 1964, quien será la propietaria de As hasta 1996, cuando PRISA compró el diario. 
El primer director de $A s$ fue Luis González de Linares, contribuyó a la creación del diario y, cuatro años más tarde, a la de $A s$-Color, asumiendo también su dirección ${ }^{3}$.

Muy pronto, durante la década de los setenta, As superó en ventas a Marca, su principal competidor en lo que a prensa deportiva madrileña se refiere. De hecho, de 1973 - con 167.000 lectores al día - a 1975 - 331.000 lectores día -, As fue el diario de mayor difusión superando incluso a $A B C$ y Pueblo. As mantuvo el liderato entre los diarios deportivos hasta que en 1988 con 389.000 lectores al día fue superado por su competidor Marca, con 23.000 lectores más, convirtiéndose en el segundo diario deportivo más vendido en España, puesto que mantiene hoy en día.

En los años 90, $A s$ se convirtió en el primer diario con todas sus páginas a color. Tras unos años con pérdidas, el Grupo Semana pone a la venta varias publicaciones entre las que se incluye $A s$. En el verano de 1996 el Grupo PRISA adquirió el 75\% del Diario $A S$, SL, sociedad editora del periódico deportivo As. La nueva empresa mantendría el mismo equipo de trabajadores a las órdenes del Grupo de la familia Montiel, salvo en los cargos directivos en los que el director Julián García Candau da paso a Alfredo Relaño, su actual director ${ }^{4}$.

En 1997, As vendía 123.447 ejemplares diarios, lo que le colocaba en tercer lugar entre la prensa deportiva, muy lejos del Marca (458.441, y muy cerca del segundo, Sport (131.140). En esto años sufre una reconversión técnica y de personal. A partir del año 2000 inicia una recuperación y en el año 2005 supera el millón de lectores al día, llegando a ofrecer sus mejores datos el pasado año 2012, con 1.480 .000 de lectores al día.

En la actualidad sigue centrándose en el fútbol dando especial cobertura a los equipos madrileños de mayor tradición Real Madrid y Atlético de Madrid, pero también informa sobre otras disciplinas deportivas.

\subsection{Sport}

Fundado por Josep María Casanovas (Grupo Mundo) y editado en Barcelona, el diario Sport apareció en los quioscos el 3 de noviembre de 1979. Desde el principio apuesta por una "importante innovación tecnológica, se trataba del primer diario español con paginación a color, y en un formato inusual que ha conservado y ha marcado su personalidad" (Alcoba, 1999: 72).

En 1979 se editaban en Barcelona una revista deportiva, Top $B a r c ̧ a^{5}$, y tres diarios deportivos: Mundo Deportivo, Dicen y 424. La salida al mercado del diario Sport condujo a la desaparición del 424 en 1980 y, a la larga, en 1985, de Dicen. Además,

3 También era el director de la revista Semana (As, 07-12-2007:14).

4 Desde su aparición en 1967, As ha contado solo con cuatro directores: Luis González de Linares (1967-1981); Rafael Gómez Redondo (Rienzi) (1981-1993); Julián García Candau (1993-1996); Alfredo Relaño (1996- actualidad).

5 La revista Top Barça, editada en Barcelona por Josep María Casanovas y Antonio Hernáez, es el germen del diario Sport, además de su editor, la gran mayoría de la primera redacción 
diez años después de su salida llega a superar en número de lectores ${ }^{6}$ al diario Mundo Deportivo, su directo competidor en la actualidad.

Desde el primer momento Sport marcó una línea editorial barcelonista y junto a la información siempre había opinión. En un formato pequeño, fue el primer diario deportivo que apostó por el impacto visual de las fotografías a color y también el primero en salir todos los días de la semana en color (Prats, en Sport 25 años, 2004: 14-16).

En 1992 el diario Sport vive una de sus decisiones más importantes al entrar a formar parte del Grupo Zeta, lo que le supondría un impulso en su crecimiento en difusión pero, como aseguró desde el primer momento su director Antonio Asensio ${ }^{7}$, en ningún momento supone un cambio en el personal ni en la línea editorial del periódico. El mayor cambio que introducen es incluir en las páginas centrales un cuadernillo, a modo de revista, con reportajes, entrevistas, infografías y fotos.

En 1993, ya como parte del Grupo Zeta, estrena el 29 de junio nuevas instalaciones, en lo que hasta ese momento había sido un antiguo almacén de víveres. La redacción se establecía de forma funcional adecuada a sus necesidades y con una red de ordenadores Macintosh con sistema de autoedición (Alcoba, 1999: 72). Sólo dos años después de entrar en Grupo Zeta, superaban por primera vez la cifra de los 100.000 ejemplares. En 1996 introducen el sistema de multi-impresión, comenzando en Vigo, y continuando con Burgos, Madrid, Zaragoza, Plasencia, Alicante, Córdoba y Las Palmas (Prats, en Sport 25 años, 2004: 14-16). Esto supuso un incremento de casi 30.000 ejemplares en un solo año. Veinte años después de su primer número el diario Sport se reinventa con un nuevo formato más grande, más color y un diseño nuevo ${ }^{8}$.

El EGM recoge datos de Sport desde 1984, con 123.000 lectores al día. La primera vez que supera el medio millón de lectores es en el año 1997, con 555.000. Durante los años siguientes retrocede pero en el año 2004 supera los 600.000; vuelve a retroceder en los años consecutivos y no supera de nuevo esta cifra hasta el año 2007, con 625.000. En el año 2010, por primera vez, supera los 700.000, con 737.000 lectores al día. En el año 2012, aunque ha perdido lectores durante los últimos dos años se mantiene como la tercera cabecera deportiva más leída. Entre los años 2011 y 2012 sus lectores se han incrementado, aunque solo en un $0,14 \%$.

y parte de la línea editorial del mismo se gestó en dicha revista (Prats, en Sport 25 años, 2004: 12)

6 Según datos del EGM el diario Sport supera en 20.000 lectores al diario El Mundo Deportivo por primera vez en 1989, en el año 2010 la diferencia entre ambos es de 79.000 lectores. El diario deportivo Sport lidera el mercado de la prensa deportiva catalana y ocupa el tercer puesto a nivel nacional, por detrás de Marca y As.

7 Desde su aparición en 1979, Sport ha contado con cinco directores Antonio Filloy (19781981); Alfredo Rueda Morellano (1981-1987); Josep Ma Casanovas (1987- 2003); Josep Prats (2003-2007); Joan Vehils (2007- actualidad).

8 La empresa Casas y Associats S.A., una compañía de consultoría periodística, fue la encargada de rediseñar el diario. 


\subsection{Super Deporte}

El diario Super Deporte, fundado en 1993 es editado por el grupo Editorial Prensa Ibérica. Dirigido por Joan Carles Martí, desde su salida, se centra en la actualidad deportiva de la Comunidad Valenciana, principalmente en el fútbol y, en un segundo plano, trata la actualidad de los equipos de baloncesto de la Comunidad Valenciana.

Super Deporte es el único periódico de tirada regional deportivo del que se conocen los datos de tirada y difusión del OJD. En 1994, tras un año publicándose, se sitúa en 8.143 ejemplares de difusión. Al año siguiente supera los 10.000, cifra en la que se mantiene hasta el año 2009 donde desciende a los 9.442. La tendencia en los últimos años ha sido al descenso con una difusión de 8.492 ejemplares en 2010 y de 6.788 para el 2012. Su tirada para este último año es de 11.109 ejemplares.

\subsection{DxT.Deporte Campeón}

El diario $d x t$, Deporte Campeón, subtitulado "Primer Diario Deportivo de Galicia”, es un periódico deportivo gallego, fundado por Ángel Hervada y Bieito Rubido. El primer número salió a la calle el 19 de diciembre de 1995, con 15.000 ejemplares y al precio de 110 pesetas. Desde su salida y hasta 1999 estaba dirigido por Cesar Casal. Juan Carlos Boga Sánchez sustituye a Casal como director y permanece en el puesto hasta el año 2009.

En la actualidad lo dirige Andrés Ríos, desde el año 2009, y forma parte del Grupo Editorial La Capital. Se centra en el deporte de la comarca coruñesa y, por extensión, de toda la provincia, aunque desde sus inicios ha intentado convertirse en el diario deportivo de toda Galicia. A lo largo de los años su cabecera ha variado, comenzó llamándose Dxt Deporte, luego DxT campeón y en la actualidad Deporte Campeón

\subsection{Estadio Deportivo}

El diario ESTADIO Deportivo", fundado en 1995 como publicación semanal, se convierte en diario el 28 de agosto de 1996. A partir de esa fecha los directores que han desarrollado su labor (durante al menos un año) han sido Manuel Vicente Navas (1996), José David Martín Laínez (1998), Bosco Martín Algarra (2003) y Joaquín Adorna León (2008 hasta la actualidad).

ESTADIO es el primer y único diario deportivo de Andalucía. Entre sus señas de identidad -además del tratamiento pormenorizado de la actualidad de los dos equipos sevillanos de fútbol, Sevilla F.C. y Real Betis Balompié- está el espacio que le dedica al fútbol base y al polideportivo local. Obviamente, también tiene cabida el fútbol nacional e internacional; así como el Polideportivo nacional e internacional.

9 La información del diario ESTADIO Deportivo ha sido facilitada por la dirección y contrastada en sus ediciones impresa y digital (http://www.estadiodeportivo.com/ed.php). 
En 1999 el diario estaba participado en un $85 \%$ por Recoletos y un $15 \%$ por el Grupo Prensa Ibérica y sólo se distribuía en Sevilla y su provincia. En el año 2007 entra a formar parte del grupo Unidad Editorial y desde el 11 de enero de 2010 se vende de manera conjunta con El Mundo, lo que produce una espectacular subida de la tirada con una media anual de 40.000 ejemplares en el 2012 (OJD).

\subsection{El 9 Espotiu de Catalunya}

El 9 Esportiu salió a los quioscos el 2 de enero del 2002, al precio de $0,50 €$, editado por el grupo Coordinadora de Medios SL. Sale con una tirada inicial de unos 70.000 ejemplares, además de los visitantes de la Web (http://www.el9.com). El 9 Esportiu de Catalunya era y es el único diario impreso deportivo escrito íntegramente en catalán.

Su primer director fue Jordi Grau, quien hasta ese momento había sido subdirector del grupo de El Punt. La directiva la completaban Jordi Camps y Pep Riera, como directores adjuntos y David Colomer como redactor jefe.

En el 2003, se introducen grandes cambios: es en este momento cuando pasa al Grupo Hermes Comunicaciones y cambia de director, Pep Riera quien se encarga de poner en marcha la publicación de tres ediciones territoriales diferenciadas en noviembre de ese año.

En la actualidad, y desde el año 2012, lo edita CECM SL. y lo dirige Emili Gispert y Negrell, como director editorial, junto con dos directores Adjuntos: FERRAN ESPADA (Actualidad) y JORDI CAMPS (Opinión, Cierre y Servicios).

\section{Conclusiones}

Los diarios deportivos van a contracorriente con respecto al resto de la prensa (EGM). Los cuatro diarios principales: Marca, As, Sport y Mundo Deportivo han ganado lectores en los últimos años.

La tendencia ascendente del total del número de lectores al día de los diarios deportivos que venía registrando desde 2001, se frena en el año 2004 con 4.043 .000 lectores, se produce un descenso en el número de lectores en los dos años siguientes, 3.958.000 en el año 2005 y 3.880.000 en el año 2006. A partir del año 2007 la tendencia ha ido en aumento, con 3.957.000 lectores, y esta tendencia continua hasta hoy. Para el período comprendido entre febrero y noviembre de 2010, la cifra total de lectores de diarios deportivos españoles ascendió a los 4.576.000 lectores al día, en el año 2011y 2012 aumenta situandose en torno a 4.731.000, para el último año.

Durante los primeros años de del siglo XXI, en el marco comparativo de estudio al conjunto de cabeceras de edición diaria en España, es decir, considerando tanto deportivas como de información general, dentro de un marco competitivo natural, 
Marca es el diario más leído por encima de los generalistas, supera por primera vez en el año 2012 los tres millones de lectores.

Siete de los ocho diarios más leídos en el año 2012, durante estos años han ganado lectores al comparar el año 2000 con el año 2012. La mayor subida la ha protagonizado As con 855.000 lectores más, le sigue Marca con un aumento de 755.000 lectores, El País con 482.000, Sport con 329.000, Mundo Deportivo con 249.000, La Vanguardia con 188.000 y El Mundo con 185.000. Únicamente, El Periódico de Catalunya, ha perdido en este período 226.000 lectores al día.

En el año 2008 los diarios generalistas comienzan a perder lectores, una tendencia que se mantiene hasta hoy, sin embargo los deportivos continúan ganando audiencia.

En el año 2012, Marca, una vez más, es el diario más leído por encima de los generalistas, con una ventaja de más de un millón de lectores sobre seguidor, El País. $A s$, que en el año 2000 ocupaba el sexto puesto de los diarios según el número de lectores, ocupa la tercera posición desde el año 2010. Sport ha pasado de la undécima posición a la sexta en los mismos años, por delante de Mundo Deportivo, que ha mejorado su puesto, de la décima a la séptima posición. En el año 2012 los diarios deportivos rompen con la mala tendencia de los periódicos generalistas y consiguen sumar nuevos lectores.

Los diarios regionales deportivos no se someten a ningún tipo de control - exceptuando Super Deporte que se somete a la Oficina de Justificación de la Difusión $(\mathrm{OJD})^{10}$ - por lo que es difícil calcular su nivel de penetración en el público. Lo que queda claro es que los cuatro analizados se mantienen en el mercado, con dificultades, y que otros han desaparecido, Depor Sport (2005-2013) - como impreso - o el Diario Equipo (1993-2009), en gran medida condicionados por los éxitos deportivos de los equipos de fútbol de la región.

\section{Bibliografía}

ALCOBA LÓPEZ, A. (1999). La prensa deportiva: tratamiento inédito sobre el género específico del deporte, y cómo hacer una publicación deportiva ideal. Madrid: Instituto Universitario Olímpico de Ciencias del Deporte.

ALCOBA, A. (2005). Periodismo deportivo. Madrid: Síntesis

ALTABELLA, J. (1988). "Historia de la prensa deportiva madrileña". En ZABALZA RAMOS, R. (Coord.). Orígenes del deporte madrileño: 1870-1936. Vol. I. Condiciones sociales de la actividad deportiva. Madrid: Comunidad de Madrid.

AS. Desde 1967 - 2013

10 La Oficina de Justificación de la Difusión (OJD) es la encargada de la realización y verificación de las cifras de difusión de las publicaciones cuyos ejemplares son vendidos a terceros a través de los distintos canales, y de las de distribución gratuita. 
ASOCIACIÓN PARA LA INVESTIGACIÓN DE MEDIOS DE COMUNICACIÓN.

Estudio General de Medios (EGM) en: http://www.aimc.es/. [10-09-2013].

BOYLE, R., ROWE, D. y WHANNEL, G. (2009). "Delight in trivial controversy? Questions for sports journalism". En S. ALLAN (Ed.). The Routledge Companion to News and Journalism (pp. 245-255). New York: Routledge

DEPOR SPORT. Desde 2005 - 2013

DXT, DEPORTE CAMPEÓN. Desde 1995- 2013

EL 9 ESPORTIU. Desde 2002 - 2013

ESTADIO DEPORTIVO. Desde 1995 - 2013

ESTEVE, F. y FERNÁNDEZ DEL MORAL, J. (2007). Información deportiva. En F. ESTEVE y J. FERNÁNDEZ DEL MORAL, Áreas de especialización periodística (pp. 273-287), Madrid: Fragua.

FERNÁNDEZ DEL MORAL, J. (Coord.) (2004). Periodismo especializado. Barcelona: Ariel.

MARCA. Desde $1938-2013$

MARRONE, J.M. (2009). La importancia de la portada en las ventas del diario Marca. [Tesis doctoral]. Universidad Complutense de Madrid.

MARTÍNEZ ALBERTOS, J.L. (1983) Curso general de Redacción Periodística. Barcelona: Mitre.

MUNDO DEPORTIVO. Desde 1906 -2013

OFICINA DE JUSTIFICACIÓN DE LA DIFUSIÓN (OJD). http://www.introl.es/. [10-09-2013].

PALACIOS, A. (1999). “Aspectos lingüísticos de la prensa deportiva: la crónica futbolística". En J. C. GARRIDO (Coord.) La lengua y los medios de comunicación. Actas del Congreso Internacional celebrado en la Universidad Complutense de Madrid en 1996 (pp. 350-361). Madrid: Editorial Complutense.

PANIAGUA, P. (2003). Información deportiva: especialización, géneros y entorno digital. Madrid: Fragua.

SAINZ DE BARANDA ANDÚJAR, C. (2013). "Orígenes de la prensa diaria deportiva: «El Mundo Deportivo»”. En Materiales para la Historia del Deporte, $N^{\circ} 11$. p. $7-27$.

SPORT (2004). Sport 25 Años. Edición especial XXV aniversario. Barcelona: Grupo Zeta.

SPORT. Desde 1979 - 2013

SUPER DEPORTE. Desde 1993 - 2013

TORO, C. (2008). Historia de Marca. $70^{\circ}$ aniversario. Madrid: La Esfera de los Libros.

\section{La autora}

Clara Sainz de Baranda Andújar. Doctora por la Universidad Carlos III de Madrid, licenciada en Periodismo (UC3M) y en Historia del Arte (UCM). En la actualidad es profesora visitante del Departamento de Periodismo y Comunicación Audiovisual, de 
la Facultad de Humanidades, Comunicación y Documentación de la UC3M, donde es responsable de laboratorios del área de Periodismo del Departamento de Periodismo y Comunicación Audiovisual. 